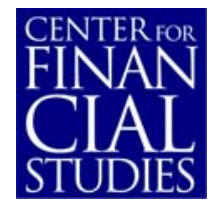

No. $2007 / 04$

On the Role of Patience in an Insurance Market with Asymmetric Information

Michael Sonnenholzner and Achim Wambach 


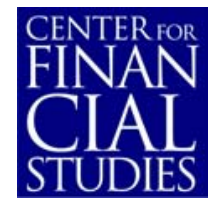

\section{Center for Financial Studies}

The Center for Financial Studies is a nonprofit research organization, supported by an association of more than 120 banks, insurance companies, industrial corporations and public institutions. Established in 1968 and closely affiliated with the University of Frankfurt, it provides a strong link between the financial community and academia.

The CFS Working Paper Series presents the result of scientific research on selected topics in the field of money, banking and finance. The authors were either participants in the Center's Research Fellow Program or members of one of the Center's Research Projects.

If you would like to know more about the Center for Financial Studies, please let us know of your interest.

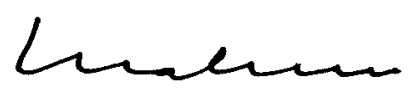

Prof. Dr. Jan Pieter Krahnen

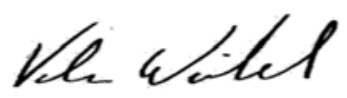

Prof. Volker Wieland, Ph.D. 
CFS Working Paper No. 2007/04

\title{
On the Role of Patience in an Insurance Market with Asymmetric Information*
}

\author{
Michael Sonnenholzner ${ }^{1}$ and Achim Wambach $^{2}$
}

\author{
This Version \\ July 12, 2006
}

\begin{abstract}
:
We analyse a 2-period competitive insurance market which is characterized by the simultaneous presence of standard moral hazard and adverse selection with regard to consumer time preferences. It is shown that there exists an equilibrium in which patient consumers use high effort and buy a profit-making insurance contract with high coverage, whereas impatient consumers use low effort and buy a contract with low coverage or even remain uninsured. This finding may help to explain why positive profits and the opposite of adverse selection with regard to risk types can sometimes be observed empirically.
\end{abstract}

JEL Classification: D82, G22

Keywords: Insurance, Patience, Adverse Selection, Moral Hazard

\footnotetext{
* We thank participants at the yearly meetings of the American Risk and Insurance Associations and the European Group of Risk and Insurance Economists and of the 1. World Risk and Insurance Congress for helpful comments. Financial support by the Staedtler Foundation Nuremberg is gratefully acknowledged.

1 Hohenzollernstraße 38, 80801 München, Germany

2 Corresponding author: Universität zu Köln, Staatwissenschaftliches Seminar, Albertus-Magnus-Platz, 50931 Köln, Germany, E-Mail: wambach@wiso.uni-koeln.de and Center for Financial Studies
} 


\section{Introduction}

Empirically, personal discount rates vary to a significant degree among people. For example, Warner and Pleeter (2001) use data from the US military downsizing program of the early 1990's to estimate the discount rates of separatees who could choose between an annuity and a lump-sum payment. Their estimates of discount rates range from 0 to over $30 \%$. Frederick et al. (2002) survey articles that try to estimate the annual discount rate of individuals. Across and within the various studies there is a tremendous variance in results which take values from zero to infinity, with some results even being negative. These findings seem to underline the relevance of accounting for different time preferences among consumers. However, this issue has to our knowledge not received attention so far in the context of insurance markets.

Since the typical insurance contract requires insurees to pay the premium upfront for several periods (e.g. months), there exists a role for time preference in the consumers' ex-ante valuation of the contract. The aim of this article is to analyze the effects of differences in the personal discount rate of individuals in a competitive insurance market. For this purpose we employ a two-period model with both moral hazard and adverse selection in the spirit of de Meza and Webb (2001). However, it is assumed that the informational asymmetry is not with regard to risk aversion but the individuals' personal discount rate, which can either be high (impatient) or low (patient). This corresponds to a low (impatient) or high (patient) discount factor. The discount factor will be used for modelling purposes throughout this article.

We show that there exists a separating equilibrium in which patient consumers use high effort and buy a profit-making insurance contract. In contrast, impatient consumers use low effort and buy a contract with lower cover than the patient consumers or even prefer to remain uninsured. In this sense, accounting for differences in the personal discount rate helps to explain both positive profits and the opposite of adverse selection ("advantageous" selection as it is called by de Meza and Webb).

This finding contrasts with traditional models of adverse selection in insurance, for example as represented by Rothschild and Stiglitz (1976), which predict that it is the high risks who are more keen on buying insurance. Furthermore, in competitive insurance markets there are usually zero profits for insurers. However, there is some evidence which does not seem to fit these predictions. Dionne et al. (2001) criticize an empirical study by Puelz and Snow (1994) which finds that adverse selection is a relevant problem for automobile insurance. They show that under refined estimation 
methods the result cannot be confirmed. Cawley and Philipson (1999) analyze whether data from life insurance is consistent with the adverse selection hypothesis. They report that in several regards the data exhibits the opposite of the expected pattern. For example, there is a negative covariance between risk and quantity. This suggests that it is actually the low risks who are inclined to buy more insurance. In an empirical study of the Australian general insurance industry, Murat et al. (2002) find that insurers are able to sustain a considerable amount of market power. This result is obtained since insurers do not completely pass on increases in their production costs to consumers. However, this would be expected from a perfectly competitive industry, as it has no leeway to bear part of the cost increases itself. A further hint that market power may exist at least in some insurance sectors comes from Nissan and Caveny (2001) who find that some lines of property and liability insurance in the US are significantly more concentrated than a comparable collection of other industries.

We also explore to what extent random contracts and differentiated contracts may allow insurers to better screen the market. We show that ex-ante randomization, where the result of the lottery is revealed before the choice of effort, can indeed achieve a better separation of types. Therefore, premiums for patient customers are driven down by competition until profits disappear. The downside of ex-ante randomization is that in this model it is equivalent to the quite unrealistic idea of throwing the dice in the insurance agent's office in order to determine which contract the insuree will be offered. A more realistic way of thinking about randomization is, when the result of the lottery is revealed only after the choice of effort. Such randomness might be achieved in practice by linking the indemnity payment to criteria which are out of the insuree's control, e.g. the precise circumstances of an accident. We show that ex-post randomization does not improve the screening capabilities of the market.

A different way of how insurers can further screen between patient and impatient customers is to make explicit use of the consumers' different time preferences. This can be done by differentiating the insurance product into a relatively expensive full service policy and a cheaper discount policy with less services. We assume that the service level is defined by the time it takes until the indemnity is paid out in case the customer reports a loss. The impatient types are inclined to buy full service insurance whereas the patient types do not mind the delayed payment of indemnities under discount insurance that much. 
This article draws on de Meza and Webb (2001) who develop a model which can explain the opposite of adverse selection in a competitive insurance market. This follows from adverse selection on risk aversion in the simultaneous presence of moral hazard. Consumers are split into timid and bold people, whereby the bold ones are less risk averse. They can choose between a high or low level of unobservable precautionary effort in order to avoid the loss. De Meza and Webb show that for certain parameter values a unique separating equilibrium exists in which timid individuals buy insurance and employ high effort whereas bold ones remain uninsured and employ low effort. In contrast to de Meza and Webb, adverse selection in the present model occurs regarding the consumers' personal time preferences.

This work is linked to the literature on multi dimensional adverse selection (Smart (2000), Villeneuve (2003), Wambach (2000)). Those models can also lead to profit making contracts where however the higher risks buy more coverage. In these models with multi dimensional adverse selection undercutting the profit-making equilibrium contract will attract (loss-making) high risks, while in our work undercutting attracts (loss-making) impatient types which exert low effort.

Theoretical models of asymmetric information in the insurance market can be grouped according to whether they employ pure adverse selection (e.g. Rothschild and Stiglitz (1976)), pure moral hazard (e.g. Arnott and Stiglitz (1988)), or a combination of both (e.g. de Meza and Webb (2001) or the present model). Both pure theories on their own suggest that in equilibrium a higher cover implies a higher risk, thus leading to a positive correlation between cover and loss probability. In a recent article, Chiappori et al. (2005) establish sets of conditions under which this positive correlation property follows also from models with simultaneous moral hazard and adverse selection. The present model satisfies one set of these conditions, which require that the consumers know their loss probabilities and their risk aversion be identical and publicly known. Interestingly, there can still be a negative correlation between loss probability and cover. The reason for this discrepancy is that different personal discount rates translate into different curvatures of patient and impatient types' present value indifference curves. This is equivalent to different risk aversions in a one-period model.

The paper is structured as follows. In section 2 we describe the model. Section 3 analyses different equilibrium configurations. In section 4, extensions to the model are provided. We conclude in section 5 . 


\section{The Model}

The model we employ in this chapter consists of a game with 4 stages throughout 2 periods:

1) Insurance companies make irrevocable offers of contracts that specify both premium $P$ and indemnity $I$.

2) Clients buy at most one contract from one insurance company. When buying insurance, a client has to pay the premium $P$ up-front.

3) The consumer decides which unobservable effort level $e$ to choose in order to avoid the loss.

4) The loss occurs or not and the indemnity is paid out in case of a loss.

Stages 1 to 3 take place in period 1, whereas stage 4 takes place in period 2 .

\section{Insurers}

There are two or more risk neutral insurers in the market who compete in contracts. There is informational asymmetry regarding the patience type of consumers: Insurers know the distribution of patience types in society, but they cannot identify the patience type of an individual who wants to buy a contract. Furthermore, the consumers' utility function, the two available effort levels and the resulting loss probabilities are also known by the insurers. This enables them to conjecture the effort level employed by insurees of each type under any contract correctly, even though effort is unobservable.

For simplicity, we make the following assumption on the discounting made by the insurers.

Assumption 1 It is assumed that the market interest rate is zero.

\section{Consumers}

It is assumed that the consumers' ex-ante expected utility $E U$ can be described by

$$
E U=U(w-P)+\delta[[1-s(e)] U(w)+s(e) U(w-L+I)]-c(e)
$$

with $U$ being a concave, time-additive utility function with exogenously given risk aversion. Premium is denoted by $P$ and indemnity by $I$. Furthermore, there is period income $w$, personal discount factor $\delta$, effort $e$ with $e \in\left\{e_{l}, e_{h}\right\}$, loss probability 
$s(e)$ with $s\left(e_{h}\right)<s\left(e_{l}\right)$, costs of effort $c(e)$ with $c\left(e_{l}\right)<c\left(e_{h}\right)$ and loss $L$. To simplify notation we define $s_{n}:=s\left(e_{n}\right)$ and $c_{n}:=c\left(e_{n}\right)$ for $n \in\{h, l\}$.

The level of effort is chosen and paid for in the first period, whereas the benefit of the effort is in effect in the future. This way of modelling effort is especially adequate when it is a technical necessity to make precautionary provisions before or at the very beginning of the insurance contract. For example, when building a house the agent can decide whether or not to use fire-retardant materials. This investment will carry on its beneficial effect over the policy period of a fire insurance. Another example is travel health insurance. Here the insuree can decide whether or not to get vaccinated before departure. Sometimes an audit conducted by the insurer in case a loss is reported allows to infer the effort level employed to a certain extent. However, a perfect inference seems to be unlikely in many cases. Then the two effort levels in this model can be interpreted as the residual consumer's discretion with regard to effort which cannot be detected in an audit anymore.

The population shall be split up in a fraction $\gamma$ of patient people with a high discount factor $\delta_{p}$ and a fraction $1-\gamma$ of impatient people with a low discount factor $\delta_{i}$

Via the implicit function theorem, the slope of the consumers' indifference curves $I C$ in the premium-indemnity space (figure 1, page 11) can be verified to be

$$
S(\delta, e, P, I):=\left.\frac{d P}{d I}\right|_{e}=\frac{\delta s(e) U^{\prime}(w-L+I)}{U^{\prime}(w-P)}>0 .
$$

For extremely low patience with $\delta=0$, the indifference curve is a flat horizontal line. With increasing $\delta$, the indifference curve becomes steeper at every given point in the premium-indemnity space (figure 1).

Given the same effort level $e$, the indifference curve of a patient type $I C_{p}$ is steeper than the indifference curve of an impatient type $I C_{i}$ for any contract $\{P, I\}$. This can be seen by computing the derivative of (1) with respect to $\delta$ :

$$
\left.\frac{\partial S(\delta, e, P, I)}{\partial \delta}\right|_{e}=\frac{s(e) U^{\prime}(w-L+I)}{U^{\prime}(w-P)}>0 .
$$

Furthermore, consumers' indifference curves are concave:

$$
\frac{d S(\delta, e, P, I)}{d I}=\frac{\delta s(e) U^{\prime \prime}(w-L+I)}{U^{\prime}(w-P)}<0
$$

In the equilibrium analysis, we sometimes make the following assumption concerning the slopes of the indifference curves. 
Assumption 2 Even under high effort $e_{h}$, a patient type $\left(\delta_{p}\right)$ has a steeper indifference curve than an impatient type $\left(\delta_{i}\right)$ under low effort $e_{l}$ for any contract $\{P, I\}$.

According to (1), this requires that $\delta_{p} s_{h}>\delta_{i} s_{l}$. This "single-crossing" condition implies that indifference curves of the patient and impatient type only cross once, even if they employ different effort levels. The typical loss probability in most lines of insurance can be considered relatively small in comparison to the typical discount rate as suggested by the literature cited above. Therefore, the condition does not seem overly restrictive as long as a low level of precautionary effort does not cause $s_{l}$ to skyrocket too much. Furthermore, the possibility of an audit may impose a lower bound on $e_{l}$. Later on we also discuss the situation where this assumption is not satisfied.

\section{Effort border}

Depending on parameter values, there may be a border line in the premium-indemnity space which describes when a certain patience type is exactly indifferent between high and low effort. To determine this effort border $E B$ we compute a consumer's advantage in expected utility from employing high effort:

$$
A(\delta):=E U_{h}-E U_{l}=\delta\left[s_{l}-s_{h}\right][U(w)-U(w-L+I)]-\left(c_{h}-c_{l}\right)
$$

If $A(\delta)$ is positive, it pays to employ high effort, whereas otherwise the individual is better off employing low effort.

In order to obtain a condition under which the individual is indifferent between high and low effort, we set $A(\delta)$ equal to zero and obtain:

$$
U(w-L+I)=U(w)-\frac{c_{h}-c_{l}}{\delta\left(s_{l}-s_{h}\right)}
$$

When the individual switches from high effort $e_{h}$ to low effort $e_{l}$ (e.g. while $P$ is constant and $I$ increases marginally), it becomes apparent from (1) that the indifference curve exhibits a kink at the effort border, as its slope becomes steeper. The indifference curve of the patient type $I C_{p}$ in figure 1 gives an example.

According to (2), the position of the kink is determined by the following factors:

- the position of the kink does not depend on $P$, so the curve of kinks (effort border) is a linear vertical line in the premium-indemnity space. 
- a larger $\delta$ moves the kink to the right in premium space, so that patient types employ high effort for levels of indemnity where impatient types would employ low effort,

- a larger difference in loss probabilities for low and high effort $\left(s_{l}-s_{h}\right)$ and a larger loss $L$ move the kink to the right in the premium-indemnity space

- a larger cost difference between high and low effort $\left(c_{h}-c_{l}\right)$ moves the kink to the left. This is also the case for a larger $w$ if $I<L$, because $U$ is concave.

If the circumstances are such that the effort border of a patience type is located at an indemnity level of zero or below, the individuals of this patience type never employ high effort.

\section{Equilibria}

We assume that at stage 2 consumers buy the best contract available. If two or more insurers offer the same optimal contract, clients randomize with equal probability. Effort is chosen accordingly. Thus we can concentrate on the decision of the insurer at stage 1 .

\subsection{Characteristics of different Equilibria}

Before analyzing equilibria of the model, we outline the properties of separating and pooling equilibria, following de Meza and Webb (2001). The outside option contract (no insurance) is denoted by $O$.

\section{Separating Equilibrium}

A separating equilibrium is characterized by the following four properties, whereby $C_{n}^{*}$ with $n \in\{i, p\}$ stands for the contract chosen by type $n$ in equilibrium.

\section{Incentive compatibility}

There must be no incentive for an impatient type to buy the contract for a patient type and vice versa:

$$
\begin{aligned}
& E U_{i}\left(C_{i}^{*}\right) \geq E U_{i}\left(C_{p}^{*}\right) \\
& E U_{p}\left(C_{p}^{*}\right) \geq E U_{p}\left(C_{i}^{*}\right)
\end{aligned}
$$




\section{Effort incentives}

Since effort is unobservable, the individual employs high effort only if this is advantageous in terms of a higher expected utility:

$$
e=\left\{\begin{array}{l}
e_{h}, \text { if } A(\delta) \geq 0 \\
e_{l}, \text { if } A(\delta)<0
\end{array}\right.
$$

\section{Participation}

Consumers cannot be forced to buy insurance, but they insure themselves voluntarily, if this results in a higher expected utility than the outside option of remaining uninsured:

$$
E U_{n}\left(C_{n}^{*}\right) \geq E U_{n}(O) \text { for } n \in\{i, p\}
$$

\section{Profit maximization}

By offering $C_{i}^{*}$ and $C_{p}^{*}$ each insurer maximizes his profit, given that $C_{i}^{*}$ and $C_{p}^{*}$ are offered by his competitors. No insurer can earn more by offering a different contract or by offering no contract at all. ${ }^{1}$

\section{Pooling Equilibrium}

A pooling equilibrium $C^{*}$ is characterized by the following three properties:

Effort incentives

$$
e=\left\{\begin{array}{l}
e_{h}, \text { if } A(\delta) \geq 0 \\
e_{l}, \text { if } A(\delta)<0
\end{array}\right.
$$

Participation

$$
E U_{n}\left(C^{*}\right) \geq E U_{n}(O) \text { for } n \in\{i, p\}
$$

\section{Profit maximization}

Given that $C^{*}$ is offered by his competitors, each insurer maximizes his profit by offering $C^{*}$.

\subsection{Analysis of Equilibria}

The situations which arise from the various parameter constellations can be grouped according to which types employ high effort at least in some area of the contract space. Possible answers are none, only the patient types or both types. Since the

\footnotetext{
${ }^{1}$ To concentrate on the economics of this problem we allow for single contract deviation only. In section 4 we consider multi contract deviations.
} 
case in which no one ever employs high effort is not very interesting, we concentrate on the latter two cases. In this section we analyse the simpler case where the impatient patient types never exerts high effort. The other case is analysed in the following section.

\section{Impatient types do not employ high effort under any contract}

The analysis in this section is characterized by the following property:

P-1 The impatient types do never employ high effort but there is a region for the patient types in the contract space where they employ high effort. Formally:

$$
\delta_{i} \leq \frac{c_{h}-c_{l}}{\left(s_{l}-s_{h}\right)(U(w)-U(w-L))}<\delta_{p}
$$

This is to say that the effort border of the impatient types $E B_{i}$ is not visible in the premium-indemnity space, as it is located at a weakly negative indemnity. However, the effort border of the patient types $E B_{p}$ is located at a strictly positive indemnity, as shown in figure 1.

\section{Separating Equilibrium}

The resulting equilibria can be seen most easily by proceeding diagrammatically. Figure 1 depicts the contract space (premium-indemnity space). The concave lines are indifference curves of the patient types $\left(I C_{p}\right)$ and the impatient types $\left(I C_{i}\right)$, respectively. At some critical indemnity level, there is the patient types' effort border $E B_{p}$. To the left of it they voluntarily employ high effort, as their expected utility is higher than under low effort. To the right of it they employ low effort. Switching to the low effort level makes the loss probability jump from $s_{h}$ to $s_{l}$. Therefore, the patient types' indifference curves have a kink at their effort border, because insurance is now more valuable again.

The insurance company's fair premium lines for high and low effort are straight lines with slope $s_{h}$ and $s_{l}$, respectively, because it is assumed that the insurer is risk neutral and that the market interest rate is zero. The fair pooling line describes all contracts which yield zero profit for the insurer, if they are bought by the whole population of patient and impatient people. This line jumps at the effort border line, as here the risk of the patient types jumps from $s_{l}$ to $s_{h}$.

Regarding equilibrium, we distinguish between two cases. This is because the relevant indifference curve of the impatient types can cut the patient types' effort border below (figure 1) or above (figure 3, page 14) the fair pooling line (point $B$ ). 


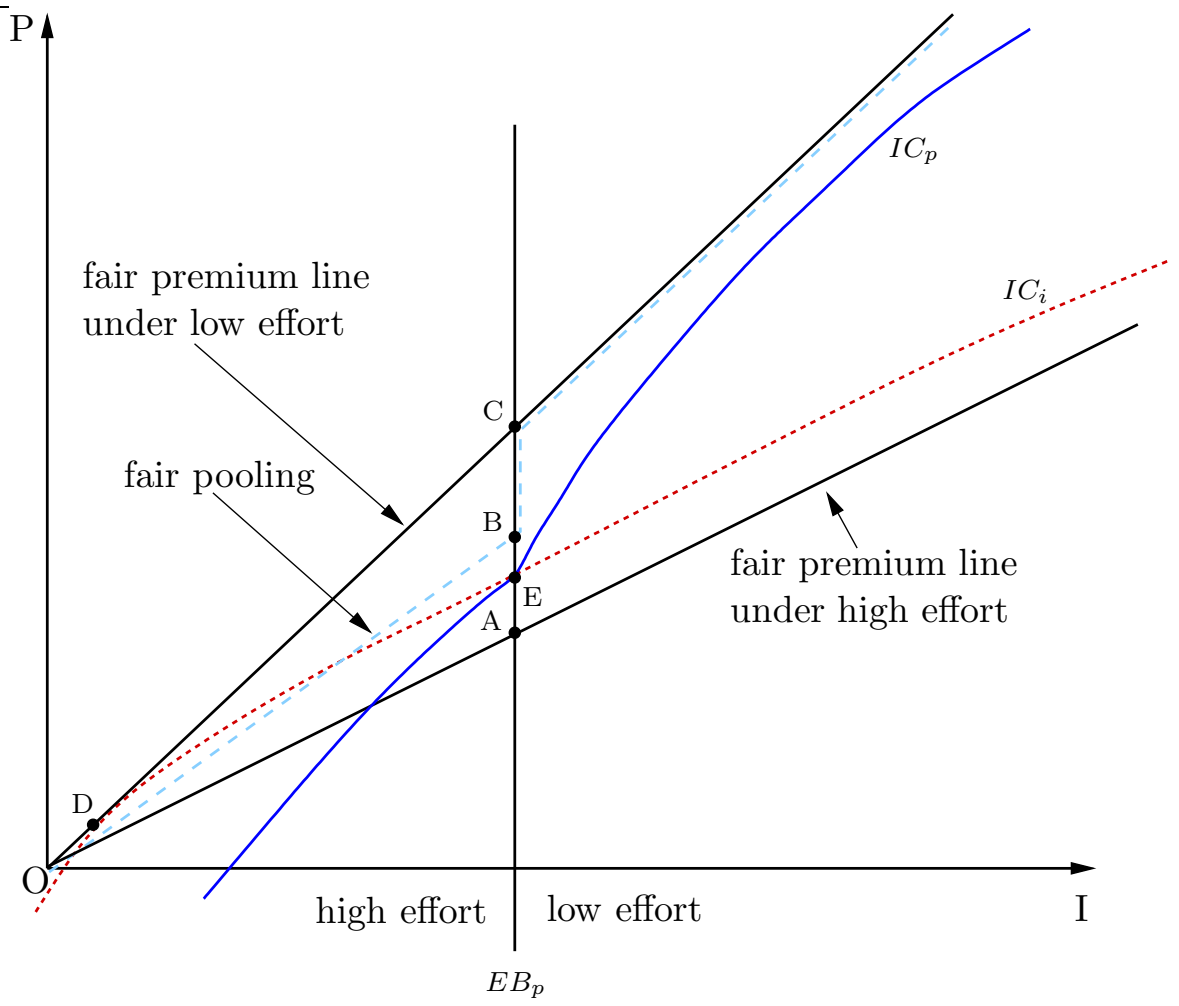

Figure 1: Contract space in a two-period competitive insurance market where consumers differ in patience. There is a unique separating equilibrium in which the impatient types employ low effort and buy zero-profit contract $D$ with low indemnity, whereas the patient types employ high effort and buy profit-making contract $E$ with high indemnity.

Proposition 1 Assume P-1 holds and that the impatient types' discount factor $\delta_{i}$ is such that $I C_{i}$ through $D$ (or $O$, if impatient types prefer being uninsured) (figure 1) cuts $E B_{p}$ above $A$ but below $B$ at some point $E$, and $I C_{p}$ through $E$ is always below the fair pooling line. If assumptions 1 and 2 hold, then there exists the following unique separating equilibrium: The patient types employ high effort and buy the profitable contract $E$. If $U^{\prime}(w)<\delta_{i} U^{\prime}(w-L)$, the impatient types employ low effort and buy zero-profit contract D which has lower cover than contract E. Otherwise, the impatient types remain uninsured.

Proof The patient types are strictly better off with contract $E$ in comparison to being uninsured. The impatient types are indifferent between contract $E$ and contract $D$ (or not being insured at all) and thus, as in Rothschild and Stiglitz (1976), it is assumed that they buy $D$.

Impatient types prefer to buy some insurance at their fair premium when $-s_{l} U^{\prime}(w-$ $\left.s_{l} I\right)+s_{l} \delta_{i} U^{\prime}(w-L+I) \geq 0$ at $I=0$. This condition is expressed in the proposition. 
Now we challenge contract $E$ by considering deviations to the left of $E B_{p}$. Offering contracts above $I C_{p}$ does not make sense. This is because below $I C_{i}$ only impatient types are attracted which results in losses. Contracts above $I C_{i}$ cannot attract any customers. By offering a contract below $I C_{p}$ an insurer could attract all patient types. However, due to assumption 2, such a contract would also attract all impatient types. Since the fair pooling line is above the deviating contract, it necessarily leads to losses.

Deviations to the right of $E B_{p}$ are also loss-making. This is because in this region both types employ low effort and the patient types cannot even be attracted away from contract $E$ by offers on the fair premium line under low effort.

The patient types prefer contract $E$ to any other contract which lies on $I C_{i}$ through $D$ (or $O$, if impatient types prefer to be uninsured) and is on or above the applicable fair premium line. Therefore, there can be no other separating equilibrium. A pooling equilibrium would have to be on or above the fair pooling line. Since $I C_{p}$ through $E$ is always below the fair pooling line by assumption, there cannot be a pooling equilibrium that would not be destroyed by $D$ (or $O$ ) and $E$. Uniqueness follows.

\section{Situation with assumption 2 not being satisfied}

An interesting question to analyze at this point is what happens when assumption 2 does not hold. This means that the indifference curve of the impatient type under low effort is steeper than the indifference curve of the patient type under high effort. Suppose that the impatient types do not want to buy insurance even for their fair premium $\left(I C_{i}\right.$ does not touch the fair premium line under low effort). Then there are two possibilities with regard to the fair pooling line: It can either cross the indifference curve of the patient types through $\mathrm{O}\left(I C_{p}\right.$ in figure 2$)$ or not. In the first case, a contract on the fair pooling line dominates $\mathrm{O}$, but it can always be destroyed by a profit-making deviating offer which only attracts patient types. In the end, no equilibrium exists. In the second case, which is shown in figure 2, $\mathrm{O}$ is an equilibrium. This shows that consumer heterogeneity with regard to time preference and simultaneous moral hazard may contribute to the fact that some risks are uninsurable. A similar result is obtained by Chiu and Karni (1998) in the context of private unemployment insurance. The authors demonstrate that adverse selection on the employees' preference for leisure together with moral hazard regarding the employees' effort of working hard can explain the absence of private unemployment 
insurance as an equilibrium outcome.

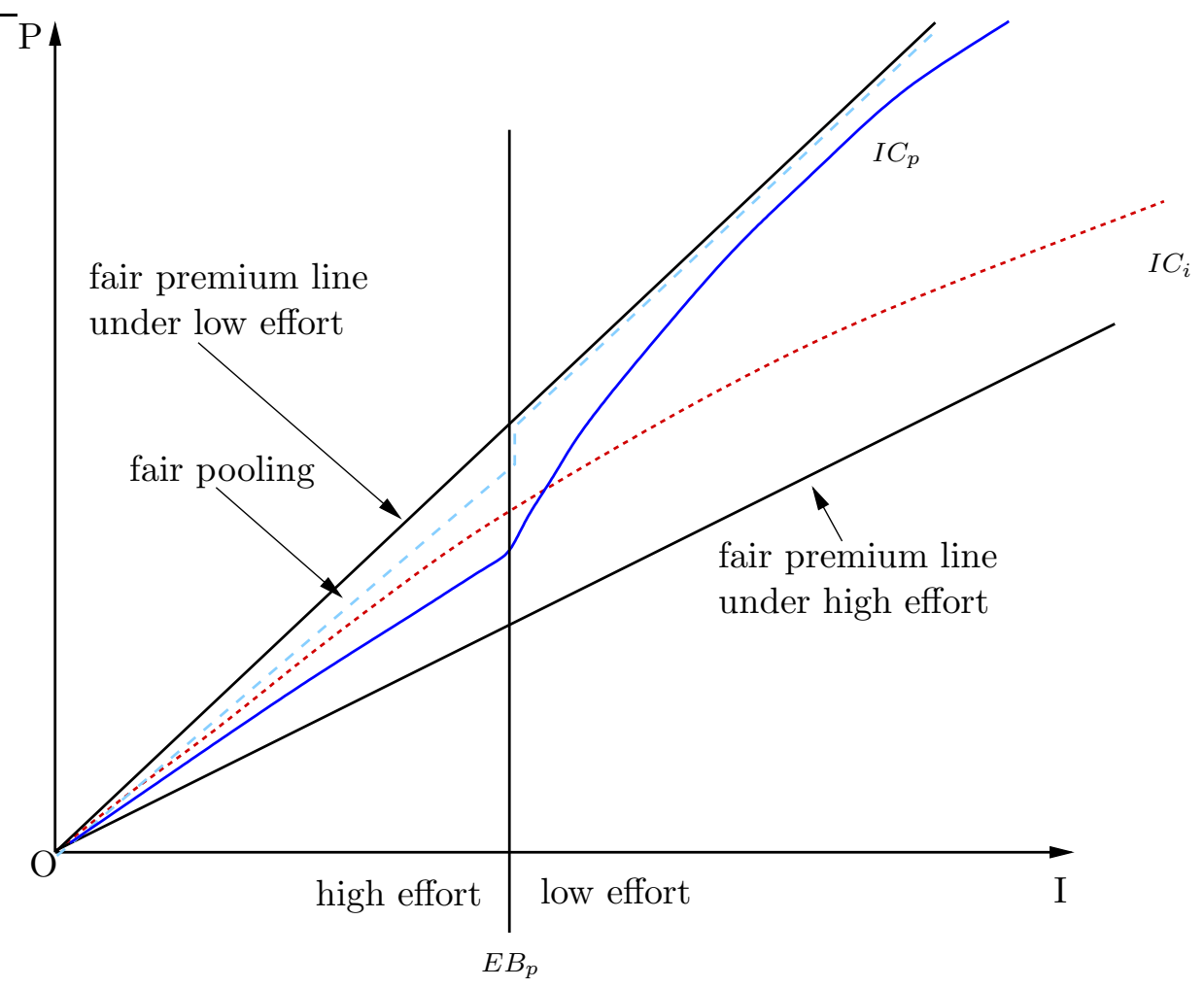

Figure 2: If assumption 2 is not satisfied, $I C_{i}$ through $O$ does not cross the fair premium under low effort and the fair pooling line does not cross $I C_{p}$, then the equilibrium contract is $\mathrm{O}$.

\section{Pooling Equilibrium}

Proposition 2 Assume P-1 holds and that the impatient types' discount factor $\delta_{i}$ is such that $I C_{i}$ through $D$ (or $O$, if impatient types prefer being uninsured) (figure 3) cuts $E B_{p}$ above $B$ but below $C$ and $I C_{p}$ through $B$ is always below the fair premium line under low effort. Under assumptions 1 and 2, there exists a unique zero-profit pooling equilibrium in which the impatient types employ low effort, the patient types employ high effort and both types buy contract $B$, if $I C_{p}$ at point $B$ is steeper than the fair pooling line to the left of $E B_{p}$ (condition $C 1$ ). Otherwise, there exists no equilibrium in pure strategies.

Proof Suppose first that condition $C 1$ holds. Both types are strictly better off buying contract $B$ instead of remaining uninsured. Now we consider deviating contracts to the left of $E B_{p}$ : Offering a deviating contract above $I C_{p}$ through $B$ 


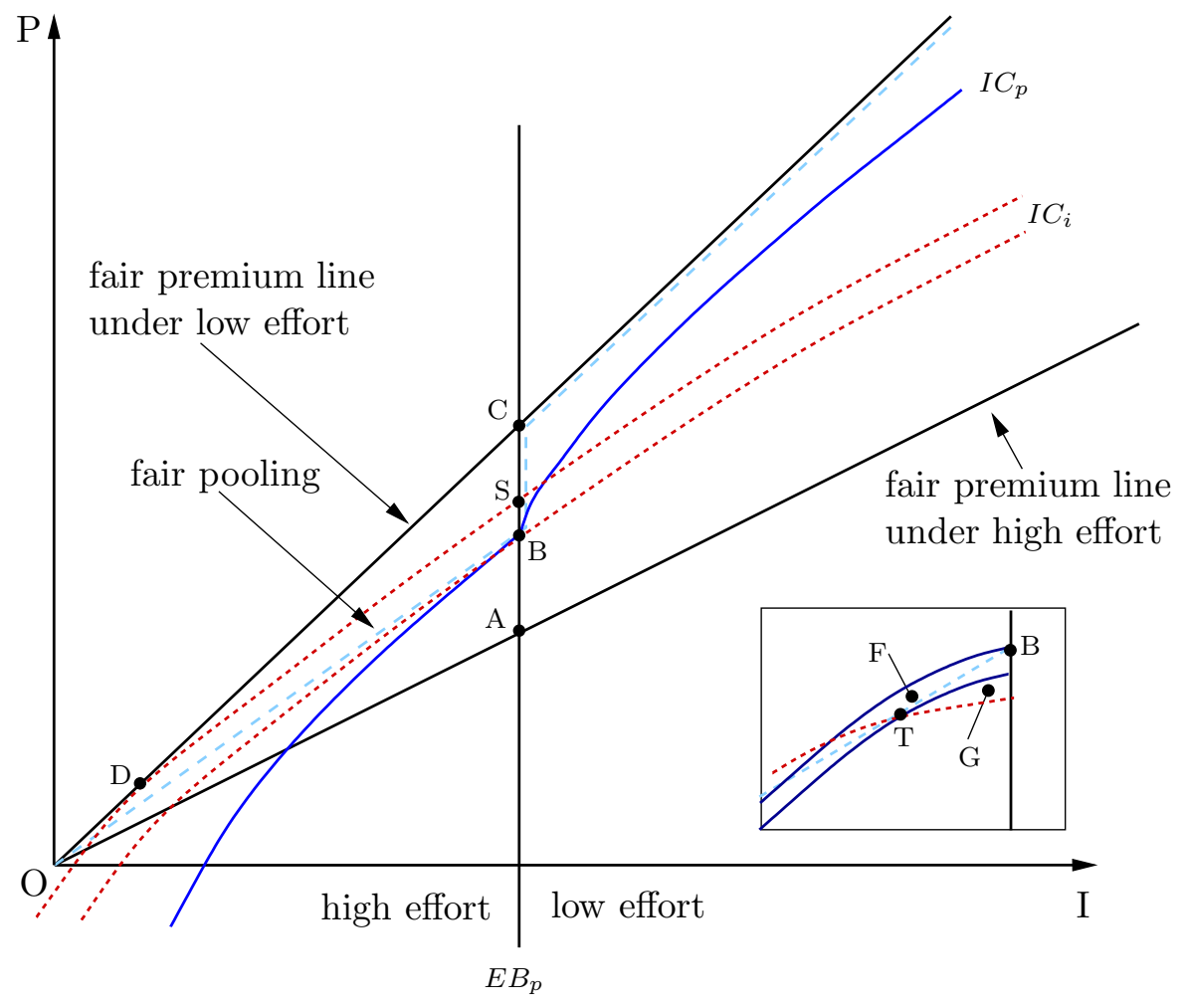

Figure 3: Unique zero-profit pooling equilibrium in which both types buy contract $B$. The impatient types employ low effort, whereas the patient types employ high effort.

does not make sense as no patient types can be attracted. Offering a profitable deviating contract below $I C_{p}$ through $B$ is loss-making since, by condition $C 1$, such contracts are below the fair pooling line and would also be bought by all impatient types (assumption 2).

Deviating contracts to the right of $E B_{p}$ are also loss-making. This is because in this region both types employ low effort and cannot even be attracted away from $B$ by contracts on the fair premium line under low effort.

The patient types prefer contract $B$ to all other contracts on or above the fair pooling line. Thus, there cannot be another pooling equilibrium. It must be that in a candidate for a separating equilibrium the impatient types get contract $D$ (or $O$, if impatient types prefer being uninsured) and are indifferent between their own contract and the contract of the patient types which would be $S$. Due to incentive compatibility, the separating contract for the patient types must be on or above $I C_{i}$ through $D$ (or $O$ ). Therefore, both types will prefer contract $B$ to the candidate for a separating contract and $B$ is a unique pooling equilibrium. 
Now we consider the situation in which condition $C 1$ does not hold which is depicted in the box in figure 3. In this case, there is a point $T$ to the left of $E B_{p}$ where $I C_{p}$ is tangent to the fair pooling line. Offering a contract like $F$ close to $T$ which attracts both types but still is above the fair pooling line destabilizes $B$. However, due to assumption 2, $T$ is also no stable equilibrium, since a profitable deviating contract like $G$ can be offered. This reasoning holds true for any contract on and above the fair pooling line. Since $I C_{p}$ is below the fair premium line under low effort there cannot be a pooling equilibrium to the right of $E B_{p}$ either.

Suppose $S$ is part of a candidate for a separating equilibrium. All insurers offering $S$ earn a profit per contract which is represented by the distance $\overline{\mathrm{AS}}$. If there are too many insurers offering $S$, a deviation slightly to the south-west of $S$ can be profitable for an individual insurer. This is the case, if the pooling profit earned by serving all consumers is greater than the share in profit by serving only

patient consumers. The consequence is that no equilibrium is possible due to the single crossing property (assumption 2) in the area to the left of $E B_{p}$. Even if there are not too many insurers offering $S$, new entrants in the insurance market are attracted and $S$ is destabilized. Thus, a separating equilibrium cannot exist. In the end, neither a pooling nor a separating equilibrium exists, if condition $C 1$ does not hold.

\section{Extensions}

\subsection{Multiple contracts}

So far we have assumed that if insurers deviate from the equilibrium, they only offer one contract each. However, in reality insurers are offering menus of contracts, which allow for the possibility of cross-subsidization of contracts. Allowing insurers to deviate with an offer of more than one contract in our model leads to the following results:

In case of a separating equilibrium (figure 1) the equilibrium will break down. First note that offering two contracts just "below" $D$ and $E$ will attract all customers away from the equilibrium contracts and will lead to a larger profit for the deviating insurer. The insurer will make losses with the contract for the impatient types, while making profits with the contract for the patient types. Cross-subsidizing contracts by themselves are never an equilibrium, as any insurer would only offer the profit making contract (if all others offer the pair of cross-subsidizing contracts). Thus no 
equilibrium exists. In case of a pooling equilibrium (figure 3) a similar result can be obtained. Offering a contract just "below" $B$ and a second one, which is on the indifference curves of the impatient type going through this contract, can lead to a profit making pair of contracts, where again the contract with the impatient type makes a loss, while the contract for the patient type makes a profit. As before, such a pair of contracts cannot be an equilibrium.

There is a huge literature on the equilibrium non-existence problem in insurance markets with adverse selection. It is probably fair to say that so far there has been no general agreed upon way on how to deal with this problem. We will discuss here two possible responses to this problem, and outline the corresponding equilibria these will lead to.

The first is the so-called WMS equilibrium approach (Wilson (1977), Miyazaki (1977) , Spence (1978)) which has found a game-theoretic basis in the work by Hellwig (1987). In this approach, cross-subsidizing equilibrium contracts are possible, as for any deviating menu of contract, the insurers can react by withdrawing their contracts. Thus if someone intends to cream skim the market by offering the profit making contract only, the others will withdraw their contracts so that the deviating insurer is left with all customers and makes a loss. In our model a WMS equilibrium is given by contract pairs of the form described in the previous paragraph: The patient type receives a contract on his effort border line, which is such that he employs high effort and the insurer make profits with this contract. The impatient type obtains a contract on his indifference curve going through the contract for the patient type. Insurers make losses with this contract which are such that they on average exactly equal the profits made with the patient type. Thus the result that the higher risks buy the contract with smaller coverage remains to hold, while the results on the profit making contract and on pooling contracts do not hold anymore.

A second approach to the equilibrium non-existence problem is the Riley equilibrium, the consequences of which have found a game theoretic basis in the work by Inderst and Wambach (2001). Riley assumes that if deviating contracts are offered, the other insurers can respond by offering new contracts themselves. This makes offering cross-subsidizing deviating contracts unattractive, as the other insurers will respond by offering only the profit making contract. Therefore the deviator is left with all the high risks and only a few if any low risks. In Inderst and Wambach it is assumed that insurers are capacity constrained. In that case deviating by offering cross subsidizing contracts might lead to a loss as only the high risks will come to 
buy the new (loss making) contract from the deviating insurer. Although a low risk would also profit from the new (profit making) contract he might not approach the deviating insurer if there are some small costs of doing so. The reason is that as many high risks will come, and as the insurer is capacity constrained, the insurer will not have sufficiently many resources to cover the whole market. In our model the Riley equilibrium takes the form as discussed in the previous section (in Figures 1 and 3). Profit making separating contracts as well as pooling contracts remain to exist in equilibrium. Any cross-subsidizing deviation will become unattractive if other insurers can react or if only the impatient types approach such a deviator. This in turn justifies why we concentrated in the previous section on the simpler analysis of allowing for single contract deviations only.

\subsection{Random contracts}

In this section we analyze in how far random contracts can be used by insurers in order to compete for profitable customers. ${ }^{2}$ Along the lines of Arnott and Stiglitz (1988), we can distinguish two cases with regard to timing: The realization of the lottery can be made known to the consumer either before (ex ante) or after (ex post) his choice of effort.

Under ex-ante randomization we can think of the consumer committing to accept a contract which is the outcome of a lottery $L$ played subsequently at the insurance agent's office. The resulting contract is immediately made known to the consumer who can then decide which effort level to employ. Consider contract $E$ in figure 1. As pointed out above, there is no profitable way for an insurer to undercut $E$ with a deterministic contract. However, an insurer could offer a lottery $L=\{(E, X) ;(\mu, 1-\mu)\}$ instead of contract $E$. This lottery would imply to offer contract $E$ with probability $\mu$ and contract $X$ with probability $(1-\mu)$, whereby $X$ is somewhere on $I C_{i}$ through $E$ to the right of $E B_{p}$. Contract $E$ is profitable, whereas $X$ is loss-making. Therefore, there is a certain mixing probability $\mu$ for each possible $X$ for which the lottery yields zero profit for insurers. Furthermore, such a lottery $L$ is strictly preferred by a patient consumer in comparison to the deterministic contract $E$, because there is a probability $1-\mu$ of being better off. An impatient consumer has nothing to gain from such a lottery, since both contracts $E$ and $X$ offer exactly the same utility to him. In this situation, the introduction of

\footnotetext{
${ }^{2}$ We thank Bertrand Villeneuve for suggesting this issue. Random contracts within an insurance framework are also discussed by Arnott and Stiglitz (1988), Prescott and Townsend (1984) and Villeneuve (2003).
} 
random insurance contracts indeed enables insurers to compete further for profitable clients even at point $E$ in figure 1, until zero profits are reached.

Under ex-post randomization, the consumer is presented a lottery and commits to buying whatever contract will be the outcome. However, the uncertainty is resolved only after the choice of effort. In the present setting, ex-post randomization is more realistic than ex-ante randomization which is not observed in practice. As pointed out by Villeneuve (2003), ex-post randomization can be achieved by linking the insuree's reimbursement to criteria which are random themselves. For example, insurers can evaluate the precise circumstances of the loss. If the insuree is found to have been negligent, this allows for reducing the coverage payment accordingly. However, the legal definition of negligence most often will offer quite some room for interpretation. Generally, there are many aspects with regard to the circumstances under which the loss occurred which are out of the insuree's control, e.g. time or weather.

The question is now whether an ex-post randomized indemnity payment, which is compensated by a higher expected value of the indemnity, can achieve a better separation of types. The answer is no, which can be seen by the following argument. The expected utility of a patient type with a contract with a random indemnity who exerts high effort is given by:

$$
E U_{p}=U(w-P)+\delta_{p}\left[\left(1-s_{h}\right) U(w)+s_{h} U(w-L+I+\tilde{\epsilon})\right]-c_{h}
$$

The random variable $\tilde{\epsilon}$ with $E(\tilde{\epsilon})=0$ represents the randomness of the indemnity. There exists some $\hat{I}<I$ such that the utility of the patient type stays the same when getting the the sure indemnity $\hat{I}$ instead of the random indemnity, i.e.

$$
\begin{aligned}
E U_{p} & =U(w-P)+\delta_{p}\left[\left(1-s_{h}\right) U(w)+s_{h} U(w-L+I+\tilde{\epsilon})\right]-c_{h} \\
& =U(w-P)+\delta_{p}\left[\left(1-s_{h}\right) U(w)+s_{h} U(w-L+\hat{I})\right]-c_{h}
\end{aligned}
$$

Note that the certain indemnity $\hat{I}$ would be the same for the impatient type, i.e. it holds:

$$
\begin{aligned}
E U_{i} & =U(w-P)+\delta_{i}\left[\left(1-s_{l}\right) U(w)+s_{l} U(w-L+I+\tilde{\epsilon})\right]-c_{l} \\
& =U(w-P)+\delta_{i}\left[\left(1-s_{l}\right) U(w)+s_{l} U(w-L+\hat{I})\right]-c_{l}
\end{aligned}
$$

This is because both types have the same utility function and hence the same risk aversion. As in Arnott and Stiglitz (1988), the lottery over indemnities can be replaced by the same certainty equivalent indemnity. In the end, a randomized indemnity payment cannot achieve a better separation of types which is in line with Arnott and Stiglitz' (1988) proposition 10. 


\subsection{Impatient types employ high effort under some con- tracts}

\section{Basic Analysis}

This case shall be characterized by the following properties P-2 and P-3 which ensure that both types want to buy insurance.

P-2 Both the impatient as well as the patient types employ high effort in some region of the contract space. Formally:

$$
\frac{c_{h}-c_{l}}{\left(s_{l}-s_{h}\right)(U(w)-U(w-L))}<\delta_{i}\left(<\delta_{p}\right)
$$

The parameters in (2) take values for which the indifference curves of both types feature a kink.

P-3 The impatient types are interested in buying insurance at their fair premium under high effort.

This property requires the slope of the impatient types' indifference curve without insurance $(P=0$ and $I=0)$ not to be flatter than the fair premium line under high effort. This is captured by the following condition:

$$
s_{h}<\frac{\delta_{i} s_{h} U^{\prime}(w-L)}{U^{\prime}(w)}
$$

Proposition 3 Assume that P-2 and P-3 hold and that the impatient types' discount factor $\delta_{i}$ is such that $I C_{i}$ through $D$ (figure 4 ) cuts $E B_{p}$ above $A$ but below $B$ at some point $E$, and $I C_{p}$ through $E$ is always below the fair pooling line. If assumptions 1 and 2 hold true, then there exists a unique separating equilibrium in which both types employ high effort. The patient types buy profit-making contract $E$ and the impatient types buy zero profit contract $D$.

Proof Both types are strictly better off than without insurance. The impatient types are indifferent between their own contract $D$ and the patient types' contract $E$. Therefore, it is assumed that the impatient types buy their own contract $D$. Deviations from $D$ are not an issue, as $D$ maximizes the impatient types' expected utility subject to a zero profit by construction.

Deviations from $E$ to the left of $E B_{p}$ : It does not pay to offer a contract above $I C_{p}$ through $\mathrm{E}$. This is because above $I C_{i}$ through $D$ no customer can be attracted. 


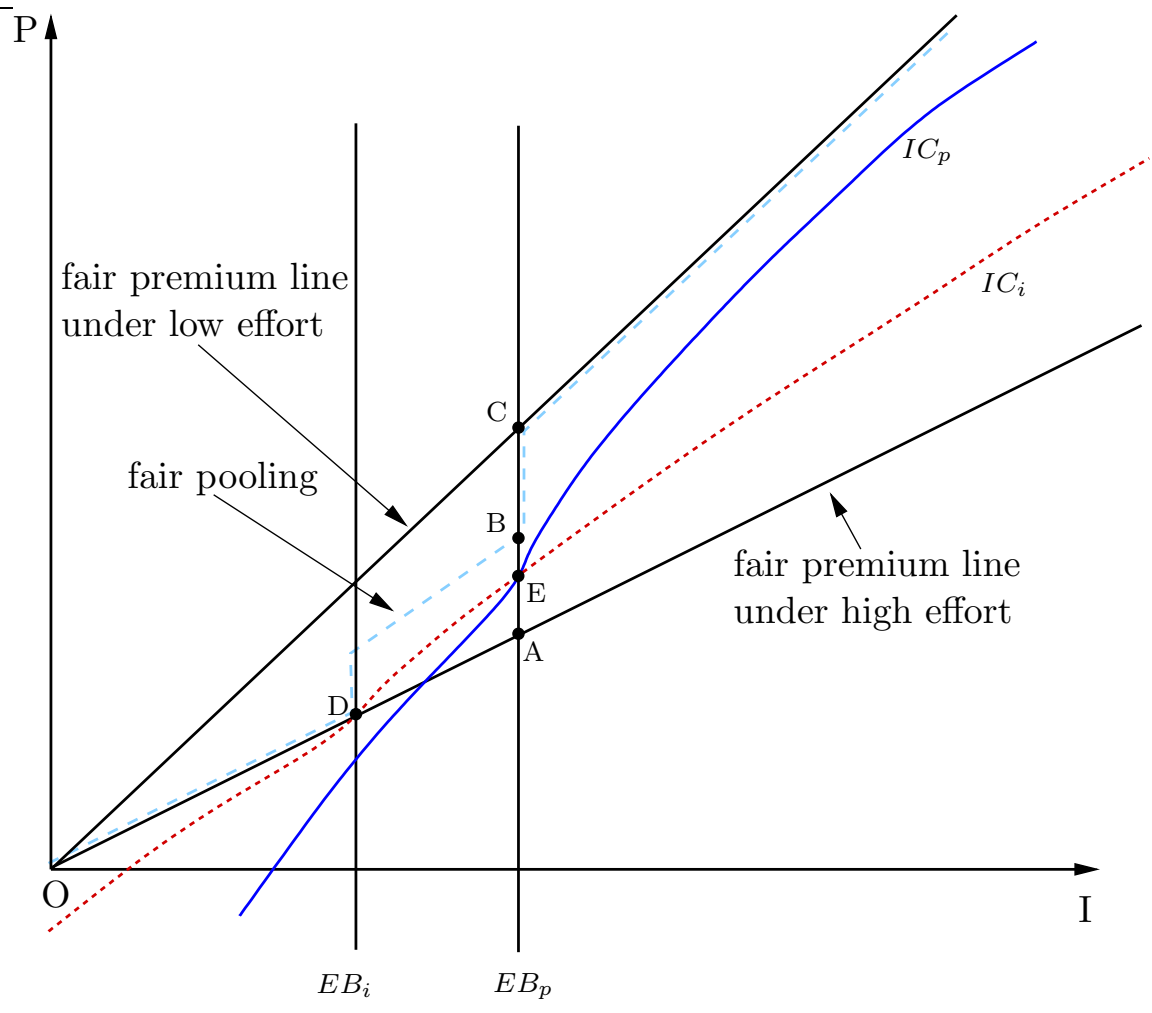

Figure 4: Both types feature a kink in their indifference curves. There is a separating equilibrium in which both types employ high effort. The patient types buy contract $E$ (profit-making) whereas the impatient types buy contract $D$ (zero profit).

Below it, only impatient types who employ low effort can be attracted, what leads to losses. This also holds true for all points on $I C_{i}$ through $D$, with the only exemption being $D$, since $I C_{i}$ does not cross the fair pooling line to the right of $E B_{i}$ as we look at the case where $E$ is below $B$. However, offering $D$ instead of $E$ is not attractive either, because it involves zero profits. Below $I C_{p}$ through $E$ both customer types are attracted due to assumption 2. However, since this area is below the fair pooling line, deviating offers below $I C_{p}$ through $E$ cause losses as well.

To the right of $E B_{p}$, profitable offers are not possible either. In this region, not even offers on the fair premium line can attract any patient customers away from E.

The patient types prefer contract $E$ to any other contract which lies on $I C_{i}$ through $D$ and is on or above the applicable fair premium line. Therefore, another separating equilibrium cannot exist.

A pooling equilibrium would have to be on or above the fair pooling line. Since $I C_{p}$ through $E$ is always below the fair pooling line, there cannot exist a pooling 
equilibrium which would not be destroyed by $E$. Uniqueness follows.

\subsection{Full service versus discount insurers}

We use the separating equilibrium of the previous section (figure 4) as a starting point and assume now that the insurers can be separated into full service insurers as well as discount insurers with a less attractive service. ${ }^{3}$ Service quality shall be represented by the following stylized fact: Full service insurers are characterized by a quick and hassle-free payout of indemnities in case the customer reports a loss. Discount insurers, in contrast, pay indemnities only with a delay. This might be because they want to save costs by having fewer staff who process claims or by earning interest on withheld indemnities.

An alternative interpretation of this specification could be in terms of exclusive agents versus independent agents. Kim and Smith (1996) suggest that exclusive agents are more reluctant when it comes to paying out indemnities while independent agents provide a better service regarding claims settlement. This is because they can threaten to move their customers to a different insurer if claims are not settled fairly and promptly.

The expected utility of an individual buying full service insurance is unchanged with regard to the situation before and given by

$$
E U^{F}=U\left(w-P^{F}\right)+\delta\left[[1-s(e)] U(w)+s(e) U\left(w-L+I^{F}\right)\right]-c(e),
$$

where superscript $F$ stands for full service insurance.

The expected utility of a consumer buying discount insurance is

$$
E U^{D}=U\left(w-P^{D}\right)+\delta\left[[1-s(e)] U(w)+s(e) U\left(w-L+t(\delta) I^{D}\right)\right]-c(e)
$$

where superscript $D$ stands for discount insurance. We assume that a discount insurer pays out indemnities with a delay of one period, so the indemnity is paid out in the third period only. In order to facilitate the analysis, we assume that there exists a function $t(\cdot)$, with $t(\delta)<\delta$ for $\delta \in(0,1)$ and $t^{\prime}(\delta)>0$, which transforms $\delta$ in such a way that a consumer is indifferent between receiving $t(\delta) I^{D}$ in period 2 and $I^{D}$ in period 3 .

By comparing $E U^{F}$ and $E U^{D}$, information about the relative position of indifference curves under full service $\left(I C^{F}\right)$ and under discount insurance $\left(I C^{D}\right)$ can be

\footnotetext{
${ }^{3}$ We thank Harris Schlesinger for suggesting this issue.
} 
obtained. Subtracting $E U^{D}$ from $E U^{F}$ while assuming that $E U^{D}=E U^{F}$ yields:

$$
U\left(w-P^{F}\right)-U\left(w-P^{D}\right)+\delta s(e)\left[U\left(w-L+I^{F}\right)-U\left(w-L+t(\delta) I^{D}\right)\right]=0
$$

From this equation it can be seen easily that two indifference curves $I C^{F}$ and $I C^{D}$ of a particular patience type $\delta$, representing the same expected utility and the same effort level, intersect at the same $P$, if $I^{F}=I^{D}=0$. For strictly positive indemnities and $\delta<1, I C^{D}$ is below $I C^{F}$ for the same effort level. As will be pointed out in the next paragraph, $I C^{F}$ becomes steeper due to the switch to low effort at a lower indemnity than $I C^{D}$. Therefore, $I C^{D}$ is also below $I C^{F}$ for indemnities for which the effort level is not the same under the two different forms of insurance. A graphical illustration is given in figure 5. Indifference curves $I C_{p}^{F}(E)$ and $I C_{p}^{D}(I)$ represent the same expected utility level for patient types, since they intersect at point $H$ where the corresponding indemnities are zero. In the same line of argument, $I C_{i}^{D}(J)$ represents the same expected utility level than $I C_{i}^{F}(D)$ for impatient types, since both indifference curves intersect at point $G$.

In analogy to (2), the effort border under discount insurance is described by

$$
U(w-L+t(\delta) I)=U(w)-\frac{c_{h}-c_{l}}{\delta\left(s_{l}-s_{h}\right)} .
$$

It is apparent that the effort border under discount insurance is located further to the right in the contract space, if $t(\delta)<1$.

An example of a situation with product differentiation is given in figure 5 . There are four different effort borders $E B_{n}^{m}$ and indifference curves $I C_{n}^{m}$ where $n \in\{i, p\}$ denotes the patience type and $m \in\{F, D\}$ denotes the insurance type ( $F=$ full service, $D=$ discount). Point $I$ marks the intersection of $I C_{p}^{D}(I)$ and $E B_{p}^{D}$. Point $J$ denotes the intersection of $I C_{i}^{D}(J)$ and $E B_{p}^{D}$.

Before proceeding to the analysis of equilibria, we introduce a modification of assumption 2:

Assumption 3 Even under high effort $e_{h}$, a patient type $\left(\delta_{p}\right)$ has a steeper indifference curve than an impatient type $\left(\delta_{i}\right)$ under low effort $e_{l}$ for any discount insurance contract $\left\{P^{D}, I^{D}\right\}$.

In order not to inflate the scope of this article, we want to focus on one case only: It is not possible to make the impatient types better off in comparison to full service contract $D$ with a discount contract that is not loss-making. This requires that 


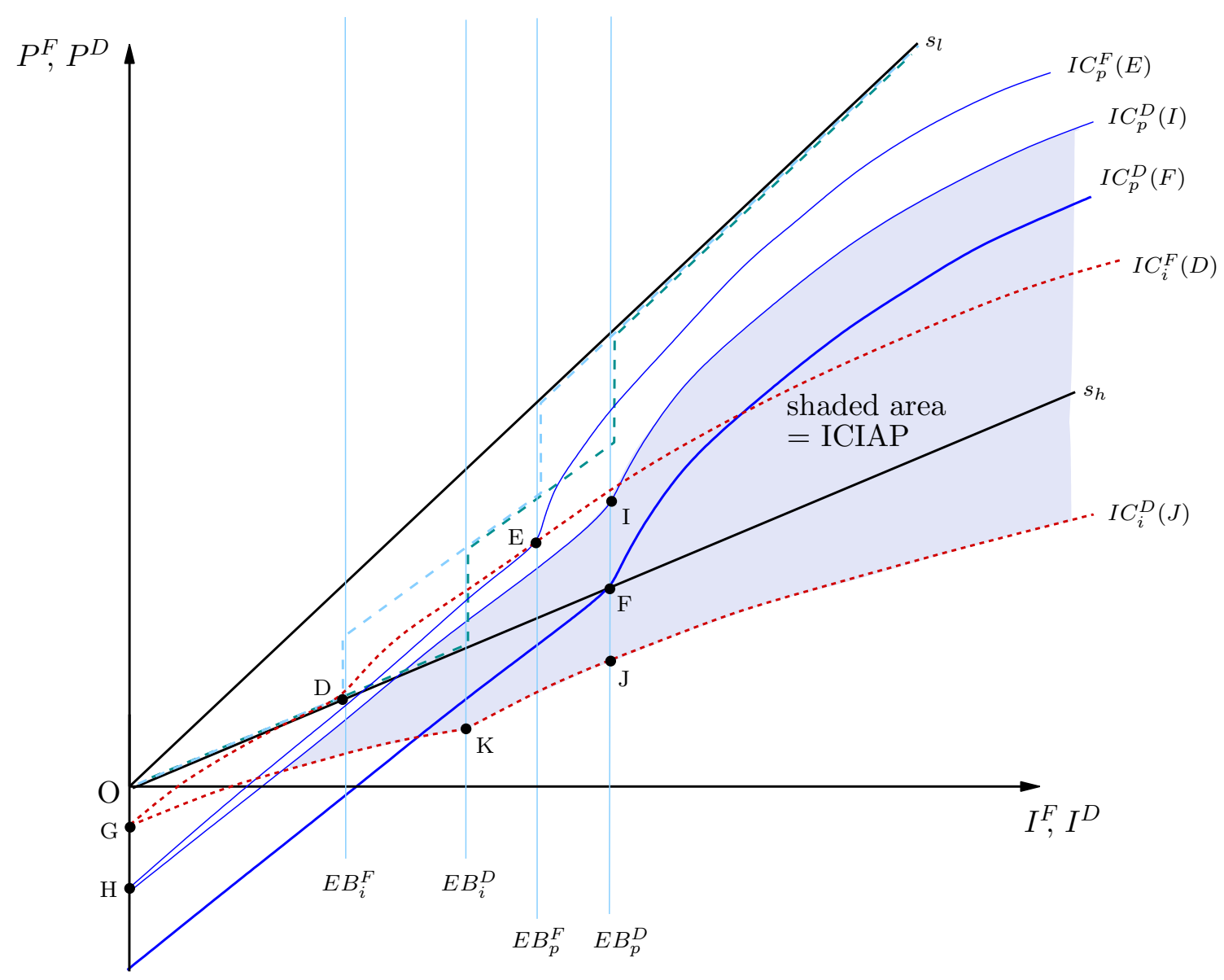

Figure 5: Situation with product differentiation in which $I$ is above $F$ and $J$ is below $F$. This allows for a separating zero-profit equilibrium in which both types employ high effort. Impatient types buy full service insurance contract $D$, whereas patient types buy discount insurance contract $F$.

$I C_{i}^{D}(J)$ (figure 5) is always below the applicable fair premium line under discount insurance, which is based on $s_{h}$ to the left of $E B_{i}^{D}$ and $s_{l}$ to the right of it.

Definition 1 The area between $I C_{p}^{D}(I)$ and $I C_{i}^{D}(J)$ which is above $s_{h}$ is defined as the "incentive compatible improvement area for the patient types" (ICIAP).

In this area, the patient types can be made better off in comparison to $E$ with a discount insurance contract without attracting impatient types away from their full service contract $D$. Furthermore, an insurer who offers a contract in ICIAP achieves at least a zero profit, if the patient types employ high effort.

Regarding the following proposition, point $F$ (figure 5) is defined to be the 
intersection of $E B_{p}^{D}$ and the fair premium line under high effort.

Proposition 4 Assume P-2 and P-3 hold in the presence of product differentiation, an $I C_{p}^{D}(I)$ which is always below the fair premium line under low effort, an $I_{p}^{D}(F)$ which is steeper than $s_{h}$ to the left of $E B_{p}^{D}$, an $I C_{i}^{D}(J)$ which is always below the applicable fair premium line and the fair pooling line under discount insurance, and an $I C_{p}^{F}(E)$ which is always below the fair pooling line under full service insurance (figure 5). If there is an ICIAP to the left of $E B_{p}^{D}$, discount insurance can attract patient customers away from the profitable full service contract $E$, and one of the following equilibria arises:

a) If ICIAP contains $F$, then a unique zero-profit separating equilibrium arises in which both types employ high effort. Impatient types buy full service contract D, whereas patient types buy discount insurance contract F (figure 5).

b) If ICIAP does not contain F, but a point like J below I on the edge of ICIAP, then a unique separating equilibrium arises in which both types employ high effort. Impatient types buy full service contract D, which yields a zero profit, whereas patient types buy discount insurance contract $J$, which yields a positive profit.

Proof If there is an ICIAP area to the left of $E B_{p}^{D}$, then insurers can make the patient types better off in comparison to full service contract $E$. In addition, insurers will achieve at least a zero profit by doing so, since only patient high effort types will be attracted by such discount policies and the ICIAP area is defined to be above the fair premium line under high effort, which is based on $s_{h}$.

Now we consider part a) of the proposition when ICIAP contains $F$. The consumers' participation constraint is met, since both contracts $D$ and $F$ make the respective consumer types better off than having no insurance.

As to stability of $D$, it is impossible to attract impatient types away from $D$ with a discount policy which would be profitable. This is because $I C_{i}^{D}(J)$ is assumed to be always below the applicable fair premium line under discount insurance and to intersect $E B_{p}^{D}$ at some point $J$ which is below $F$. Therefore, competition between insurers offering a discount policy to the patient types is not limited by the incentive compatibility constraint, as insurers run into zero profits first. Moreover, it is impossible to attract impatient types away from $D$ by offering any other full service contract which would not be loss-making. This is because $D$ is maximizing the impatient types' expected utility subject to a zero profit by construction. 
Also contract $F$ is stable. It is assumed that $I C_{p}^{D}(F)$ is steeper than $s_{h}$ to the left of $E B_{p}^{D}$. Moreover, it follows from the assumptions that it is below the fair premium line under low effort to the right of $E B_{p}^{D}$. Therefore, the best discount contract for the patient types which does not inflict losses upon insurers is the corner solution at point $F$. This contract makes the patient types employ high effort and involves a zero profit for insurers. Deviations from $F$ offering discount contracts are not an issue. In order to attract patient types away from $F$ they would have to be loss-making.

As to uniqueness, the impatient types prefer full service contract $D$ to any other full service contract which lies on or above the applicable fair premium line. Offering discount insurance to impatient customers which would provide the same level of expected utility to them as $D$ is impossible, since $I C_{i}^{D}(J)$ is assumed to be always below the applicable fair premium line. The patient types prefer discount insurance contract $F$ to any other full or discount insurance contract which is on or above the applicable fair premium line. Therefore, there can be no other separating equilibrium than $\{D, F\}$.

A discount pooling equilibrium would have to be on or above the fair pooling line under discount insurance. However, $I C_{i}^{D}(J)$ is assumed to be always below the fair pooling line under discount insurance. Therefore, the impatient types would not want to buy such a pooling contract. Since $I C_{p}^{F}(E)$ is assumed to be always below the fair pooling line under full service insurance, there can be no full service pooling equilibrium either, because it would be destroyed by $E$. Uniqueness follows.

With regard to part b) of the proposition, the participation constraint of the consumers is met as well, because both patience types are better off than without insurance.

Showing the stability of $D$ follows the same line of reasoning as under part a). However, this time competition between insurers offering discount insurance to patient types is limited by the incentive compatibility constraint, which is binding at point $J$.

Now we challenge the stability of $J$ by considering deviating discount contracts. As $J$ is below $I C_{p}^{D}(I)$, which represents indifference to $I C_{p}^{F}(E)$, deviations involving full service contracts are irrelevant, since even the best non-loss-making full service contract $E$ makes the patient types worse off than $J$.

To the left of $E B_{p}^{D}$, offering a discount contract above $I C_{p}^{D}(J)$ does not make sense: Above $I C_{p}^{D}(J)$ and below $I C_{i}^{D}(J)$ only impatient types can be attracted. To 
the right of $E B_{i}^{D}$, they employ low effort, which results in a loss. To the left of $E B_{i}^{D}$, they employ high effort, but since $I C_{i}^{D}(J)$ is assumed to be always below the fair premium line under discount insurance, this results in a loss as well. Above $I C_{i}^{D}(J)$ no customers can be attracted. Due to assumption 3, deviating offers below $I C_{p}^{D}(J)$ would attract both types of customers. However, since this region is below the fair pooling line under discount insurance, such deviations are loss-making. To the right of $E B_{p}^{D}$, there are no profitable deviations either. This is because the patient types employ low effort and can not even be attracted away from $J$ with contracts on the fair premium line under discount insurance and low effort, resulting in a loss probability of $s_{l}$.

As to uniqueness, the impatient types prefer full service contract $D$ to any other full service contract which lies on or above the applicable fair premium line. Offering discount insurance which would provide the same level of expected utility to impatient customers as $D$ is impossible without incurring a loss. This is because $I C_{i}^{D}(J)$ is assumed to be always below the applicable fair premium line. The patient types prefer discount insurance contract $J$ to any other full service or discount insurance contract which is on or above the applicable fair premium line and meets the incentive compatibility condition. As a result, there can be no other separating equilibrium than $\{D, J\}$.

A discount pooling equilibrium would have to be on or above the fair pooling line under discount insurance. However, $I C_{i}^{D}(J)$ is assumed to be always below the fair pooling line under discount insurance. Therefore, the impatient types would not want to buy such a pooling contract. Since $I C_{p}^{F}(E)$ is always below the fair pooling line under full service insurance, there can be no full service pooling equilibrium either because it would be destroyed by $E$. Uniqueness follows.

\section{Conclusion}

In this article we employ a 2-period competitive insurance model, which is characterized by the simultaneous presence of moral hazard and adverse selection. Moral hazard is modelled along the traditional lines and is assumed to occur with regard to unobservable precautionary effort which can either be high or low. However, adverse selection occurs with regard to the personal discount rate of consumers which can be high or low as well. It is assumed that consumers decide whether or not to buy insurance in the first period. If so, they have to pay the premium up-front and decide about the precautionary effort level they wish to employ. In the second 
period, the consumer faces the risk of a loss. This setup is meant to capture the fact that real world insurance contracts usually require the consumer to pay the premium up-front for several periods (e.g. 12 months) which creates a role for the consumer's personal discount rate in the ex-ante valuation of contracts.

The different time preference among consumers opens the door for separating equilibria in which the patient types employ a high effort level and buy high cover, while impatient types employ low effort and buy little or even no cover. Since high effort implies low risk and vice versa, this result is equivalent to saying that the low risks are more fond of buying insurance. Thus, the prevailing outcome is the opposite of the traditional adverse selection theory where adverse selection takes place with regard to consumer risk types. Furthermore, it is possible that the equilibrium contract for the patient types is profitable. In this case, undercutting the premium would attract all the impatient types who employ a low effort. This would result in a loss for the insurer.

Ex-ante randomization enables insurers to compete away any profits, however the validity of this concept for the real world insurance market is doubtful since it is not observed in practice. Ex post randomization, on the other hand, is not capable to increase expected utility of the patient types in comparison to the deterministic equilibrium contract. Thus there is no better separation of types and profits persist.

A further way of how profits with the patient types can be competed away is by introducing differentiated insurance products in the form of full service and discount insurance. We think of discount insurers as having a service which is not as good. We assume that the service level is defined by the (expected) delay with which an insurer pays out indemnities in case of a loss. Since patient consumers do not mind a later payment that much, this kind of product differentiation can potentially achieve a better separation of agents which allows for competing down remaining profits.

In this model we abstract from the existence of a capital market. If consumers can borrow and transfer money between periods, this will surely have a substantial impact on the power of using consumers' time preference as a screening device. However, capital market imperfections like borrowing constraints and deviations between the consumers' personal discount rate and the market interest rate might still be interesting issues to be analyzed in the context of this model. We leave this for future research. 


\section{Literature}

Arnott, R., And J. E. Stiglitz (1988): "Randomization with Asymmetric Information," RAND Journal of Economics, 19(3), 344-362.

Cawley, J., And T. Philipson (1999): "An Empirical Examination of Information Barriers to Trade in Insurance," American Economic Review, 89, 827-846.

Chiappori, P.-A., B. Jullien, B. Salanié, and F. Salanié (2005): “Asymmetric Information in Insurance: General Testable Implications," RAND Journal of Economics, forthcoming.

Chiu, W. H., and E. Karni (1998): "Endogenous Adverse Selection and Unemployment Insurance," Journal of Political Economy, 106(4), 806-827.

DE MezA, D., And D. C. WebB (2001): "Advantageous selection in insurance markets," RAND Journal of Economics, 32(2), 249-262.

Dionne, G., C. Gourieroux, and C. Vanasse (2001): "Testing for Evidence of Adverse Selection in the Automobile Insurance Market: A Comment," Journal of Political Economy, 109(2), 444-473.

Frederick, S., G. Loewenstein, and T. O’Donoghue (2002): "Time Discounting and Time Preference: A Critical Review," Journal of Economic Literature, 40, 351-401.

Hellwig, M. (1987): "Some recent developments in the theory of competition in markets with adverse selection," European Economic Review, 31, 319-325.

InDERst, R., AND A. WAMBACH (2001): "Competitive insurance markets under adverse selection and capacity constraints," European Economic Review, 45, 19811992.

Kim, J. K., And C. W. Smith (1996): "On the choice of insurance distribution systems," Journal of Risk and Insurance, 63, 207-227.

MiyazAki, H. (1977): "The rate race and internal labour markets," Bell Journal of Economics, 8(2), 394-418. 
Murat, G., R. Tonkin, and D. Jüttner (2002): "Competition in the General Insurance Industry," Zeitschrift für die gesamte Versicherungswissenschaft, $3,453-481$.

Nissan, E., And R. Caveny (2001): "A Comparison of Large Firm Dominance in Property and Liability Insurance with Major Industries," Journal of Insurance Issues, 24, 58-73.

Prescott, E. C., and R. M. Townsend (1984): "Pareto Optima and Competitive Equilibria with Adverse Selection and Moral Hazard," Econometrica, 52(1), $21-46$.

Puelz, R., And A. Snow (1994): "Evidence on Adverse Selection: Equilibrium and Cross-Subsidization in the Insurance Market," Journal of Political Economy, $102,236-257$.

Rothschild, M., And J. E. Stiglitz (1976): "Equilibrium in Competitive Insurance Markets: An Essay on the Economics of Imperfect Information," Quarterly Journal of Economics, 90, 626-649.

Smart, M. (2000): "Competitive Insurance Markets with Two Unobservables," International Economic Review, 41, 153-170.

Spence, M. (1978): "Product differenciation and performance in insurance markets," Journal of Public Economics, 10, 427-447.

Villeneuve, B. (2003): "Concurrence et Antisélection Multidimensionnelle en Assurance," Annales d'Economie et Statistique, 69, 119-142.

Wambach, A. (2000): "Introducing Heterogeneity in the Rothschild-Stiglitz Model," Journal of Risk and Insurance, 67, 579-592.

Warner, J., and S. Pleeter (2001): "The Personal Discount Rate: Evidence from Military Downsizing Programs," American Economic Review, 91(1), 33-53.

Wilson, C. (1977): "A Model of Insurance Markets with Incomplete Information," Journal of Economic Theory, 16, 167-207. 


\section{CFS Working Paper Series:}

\begin{tabular}{|c|c|c|}
\hline No. & Author(s) & Title \\
\hline $2007 / 03$ & $\begin{array}{l}\text { Michael Binder } \\
\text { Volker Wieland }\end{array}$ & The European Central Bank \\
\hline 2007/02 & $\begin{array}{l}\text { Francis X. Diebold } \\
\text { Kamil Yilmaz }\end{array}$ & $\begin{array}{l}\text { Measuring Financial Asset Return and Volatility } \\
\text { Spillovers, With Application to Global Equity } \\
\text { Markets }\end{array}$ \\
\hline 2007/01 & $\begin{array}{l}\text { Günter W. Beck } \\
\text { Kirsten Hubrich } \\
\text { Massimiliano Marcellino }\end{array}$ & $\begin{array}{l}\text { Regional Inflation Dynamics within and across } \\
\text { Euro Area Countries and a Comparison with the } \\
\text { US }\end{array}$ \\
\hline 2006/35 & $\begin{array}{l}\text { Christopher D. Carroll } \\
\text { Misuzu Otsuka } \\
\text { Jirka Slacalek }\end{array}$ & $\begin{array}{l}\text { How Large Is the Housing Wealth Effect? A New } \\
\text { Approach }\end{array}$ \\
\hline 2006/34 & $\begin{array}{l}\text { Giuseppe Bertola } \\
\text { Winfried Koeniger }\end{array}$ & $\begin{array}{l}\text { Consumption Smoothing and Income } \\
\text { Redistribution }\end{array}$ \\
\hline 2006/33 & $\begin{array}{l}\text { Siem Jan Koopman } \\
\text { Roman Kräussl } \\
\text { André Lucas } \\
\text { André Monteiro }\end{array}$ & Credit Cycles and Macro Fundamentals \\
\hline 2006/32 & $\begin{array}{l}\text { Rachel A. Campbell } \\
\text { Roman Kräussl }\end{array}$ & $\begin{array}{l}\text { Does Patience Pay? Empirical Testing of the } \\
\text { Option to Delay Accepting a Tender Offer in the } \\
\text { U.S. Banking Sector }\end{array}$ \\
\hline 2006/31 & $\begin{array}{l}\text { Rachel A. Campbell } \\
\text { Roman Kräussl }\end{array}$ & $\begin{array}{l}\text { Revisiting the Home Bias Puzzle. Downside } \\
\text { Equity Risk }\end{array}$ \\
\hline 2006/30 & $\begin{array}{l}\text { Joao Miguel Sousa } \\
\text { Andrea Zaghini }\end{array}$ & $\begin{array}{l}\text { Global Monetary Policy Shocks in the G5: A } \\
\text { SVAR Approach }\end{array}$ \\
\hline $2006 / 29$ & Julia Hirsch & $\begin{array}{l}\text { Public Policy and Venture Capital Financed } \\
\text { Innovation: A Contract Design Approach }\end{array}$ \\
\hline
\end{tabular}

Copies of working papers can be downloaded at http://www.ifk-cfs.de 